\title{
北京市城乡节能节水政策中长期耦合效果分析
}

\author{
刘耕源 ${ }^{1,2}$, 胡俊梅 $^{1}$, 杨志峰 $^{1,2}$ \\ (1. 环境模拟与污染控制国家重点联合实验室, 北京师范大学环境学院, 北京 100875 ; \\ 2. 北京市流域环境生态修复与综合调控工程技术研究中心，北京 100875）
}

\begin{abstract}
摘要: 本文基于长期能源可替代规划系统模型 (LEAP) 与水资源评价和规划模型（WEAP）建立了城市的能水耦合模型, 设立情景分析探讨北京市未来不同措施下城乡的节能/节水以及其耦合效果, 并对结果进行敏感性分析。模型结果表明, 未 来北京市能源消费总量将逐年缓慢增长; 按预测的供水能力则不会出现供需短缺。“十三五” 期间节水政策的总节能量为 $1.003 \times 10^{6}$ tce, 节能政策的节水量达到 $2.76 \times 10^{8} \mathrm{~m}^{3}$ 。居民生活、服务业、建筑业、传统制造业的能源需求值与水需求值具 有较好的相关性, 是重要的能水耦合部门。对于不同情景不同时期的节能/节水效果而言, 产业结构优化政策在短期可表现 出较好的节能潜力; 农业部门的灌溉技术革新与种植结构优化情景, 在短期具有较好的节能与节水效果。对于能水节约的协 同效应, 其在服务业与工业部门节能情景中较明显; 对于同一个部门的政策, 调控用能强度的情景能水协同节约效应较明显。 关键词: 北京市城乡; 节能节水; 政策耦合分析
\end{abstract}

中图分类号: F32; F42 文献标识码：A

\section{Analysis of Medium- and Long-term Coupling Effect of Energy- and Water-Saving Policies in Urban and Rural Areas in Beijing}

\author{
Liu Gengyuan ${ }^{1,2}$, Hu Junmei ${ }^{1}$, Yang Zhifeng ${ }^{1,2}$ \\ (1. State Key Joint Laboratory of Environment Simulation and Pollution Control, School of Environment, Beijing Normal University, \\ Beijing 100875, China; 2. Beijing Engineering Research Center for Watershed Environmental Restoration \& Integrated \\ Ecological Regulation, Beijing 100875, China)
}

\begin{abstract}
An energy-water coupling model is established in this paper based on long-range energy alternatives planning (LEAP) and water evaluation and planning (WEAP), scenarios are then designed to explore the energy- and water-saving effects of different policies in Beijing in the future and their coupling effects, and sensitivity analysis of the results is also conducted. Results show that the total energy consumption in Beijing will grow gradually by year, while water shortage is unlikely to occur. During the 13th Five-Year Plan, the total energy-saving amount owing to water-saving policies is 1.003 million tonnes of standard coal, and the total water-saving amount owing to energy-saving policies has reached 276 million cubic meters. The energy demand and water demand by residents' living, the service industry, the construction industry, and the traditional manufacturing industry are correlated, as they are critical energy-water coupling sectors. In terms of energy- and water-saving effects in different scenarios and periods, the industrial structure optimization policy shows great energy-saving potentials in the short term, while irrigation technology innovation and planting
\end{abstract}

收稿日期 : 2019-07-26; 修回日期 : 2019-08-20

通讯作者 : 刘耕源, 北京师范大学副教授, 主要研究方向为城市能 - 水 - 食物耦合分析、城市代谢等; E-mail: liugengyuan@bnu.edu.cn 资助项目：中国工程院咨询项目 “生态文明建设若干战略问题研究（三期）”(2017-ZD-09)

本刊网址：www.engineering.org.cn/ch/journal/sscae 
structure optimization in the agricultural sector have both good energy- and water-saving effects in the short term. A coordinated energy- and water-saving effect can be found in energy-saving scenarios in the service industry and the industrial sector. As for policies in the same sector, regulation on energy use intensity can achieve an obvious coordinated energy- and water-saving effect.

Keywords: urban and rural areas in Beijing; energy and water-saving; policy coupling analysis

\section{一、前言}

北京是我国的政治、经济、文化中心，其人口 与产业高度密集, 城乡用能用水量较大。从用水的 角度来说, 在一定程度上可以认为水资源的短缺制 约了北京市城乡的发展。从用水角度分析, 农业用 水的总量与占比均逐年下降, 源于农业播种面积的 缩水以及灌溉节水技术的推广 [1]。工业用水总量 也出现明显下降, 而居民用水总量却呈现上升势头。 从用能角度分析, 能源从开采、洗选、运输到终端 的利用依赖于大量的水资源消耗，水的取用、净化、 供给、运输及终端使用均离不开其支持。水资源通 过洗选煤炭、水力发电、太阳能板制造等活动与能 源使用联系在一起。能源通过汲取地下水、远距离 调水、污水净化等活动与其进行关联, 两者在经济 学上呈现互补品的特质 [2]。北京目前面临着严峻 的能水资源利用形势：首先，随着人口增加与产业 扩张, 北京城乡能源与水资源需求量均呈现增长趋 势; 其次, 从供给来看, 不论是能源还是水资源都 极度依赖他省供给。

过去, 节能与节水是缓解城乡能水资源短缺 的有效方式，通过设定用能用水标准、相关法律法 规以及重点节能节水技术推广目录等多种措施与 手段, 可发挥节能节水的协同效果。在 “十一五” 期间, 通过工业各部门标准的出台、法律法规的 完善、节能减排投资的增加等手段，工业部门的 节能措施发挥了较好的节能效果, 主要工业部门 的节能量达到全国总能源消耗的 $9.2 \%$, 同时也带 来了较好的节水效果 [3]。工业各部门的情况有 所不同, 建材行业的节能政策可以同时带来实现 $20.45 \%$ 的能源节省与 $15.91 \%$ 的直接节水, 因其 产业链长故可产生较好的能 - 水节约协同效果; 而在轻工业重点行业, 其节能占比可达到 $23.65 \%$, 节水比例则仅有 $1.83 \%$ 。

在用水密度较高的农业部门，不同的节水政策 也具有不同的节能潜力。文献表明, 在农业灌溉过
程中, 滴灌方式节能的潜力要比喷灌方式节能潜力 大, 地表水灌溉的最大节能潜力为 $7.1 \times 10^{8} \mathrm{~kW} \cdot \mathrm{h}$, 这一数值占北京市当年总用电量的 $1.713 \%$ [4]; 农 业用水灌溉总量的最大节能潜力为 $6.16 \times 10^{8} \mathrm{~kW} \cdot \mathrm{h}$, 是北京市当年总用电量的 $1.486 \%$ 。

北京在 “十二五” “十三五” 期间已设定城乡 能源强度和用水强度的约束性目标, 但是两者目标 的制定过程并没有考虑其间的紧密关联。此外, 在 能水节约政策制定、实施的过程中仍存在短期效果 好, 中长期目标不协调、失灵等状况。对于节能而 言, 目前的总能源规划未充分考虑水资源的约束, 与工业用水 “三条红线” 可能存在冲突 [5]。此外, 目前北京市的节水管理以计划用水、颁发取水许可 证等行政手段居多, 城乡居民参与度较低, 居民节 水意识仍有待加强 [6]。南水北调对北京水资源供 给格局产生一定的影响, 对原有的水资源系统产生 一定冲击, 其中长期效果还未知, 在工程运行之后 的配置与调度管理也有待进一步研究 [7]。本研究 将针对北京市各城乡规划中的能水相关政策, 评估 其短 - 中 - 长期耦合效果, 寻求协同发展的路径, 实现未来北京市城乡的能水可持续发展。

\section{二、基于耦合理念的城乡能水利用动态预测 模型文献综述}

对决策管理者而言, 为设计持续高效的能水利 用系统, 需要对不同的发展情形进行模拟 [8], 这 依赖于动态模型工具。目前有几种动态建模方法 被用于城市能水耦合研究中, 包括系统动力学模 型 [9]、可计算一般均衡模型 [10,11]、改进的能源 模型 [12]、改进的水资源模型 [13]。

其他研究也曾使用长期能源可替代规划系统 模型（LEAP）与水资源评价和规划模型（WEAP） 关联的模型来研究工程项目、部门、城市、区域尺 度的能水耦合系统。斯德哥尔摩环境研究所作为 WEAP 与 LEAP 模型的提出者, 使用了该方法研究 
海水淡化、区域输水管道等具体工程项目，分析项 目对于能源消费、水资源和地区温室气体排放的影 响 [14]。有学者基于 LEAP-WEAP 关联模型建立了 加拿大西部阿尔伯塔省电力部门的水消耗和温室气 体排放模型, 给出 9 个情景的温室气体节约潜力以 及用水量和温室气体减排成本 [15]。有学者建立了 城市尺度下的能源 - 水耦合利用 LEAP 与 WEAP 关联模型, 以厦门为例, 设计 11 个情景, 探讨供 需双方不同因素对城市能水耦合关系的影响, 使 用 LEAP-WEAP 关联模型以中国宁夏为案例研究能 水关系 [16]。作者测算了能源系统的用水和水资源 在利用过程中的耗能, 将宁夏分成了五个地市级区 域, 对区域分别构建了 WEAP 与 LEAP 模型, 通 过模型定量计算指出未来宁夏能源系统将面临严重 的水资源缺口, 长期内可以通过推广节能节水技术 和进行政策引导改善能水系统之间的关系 [17]。基 于 LEAP-WEAP 关联模型探讨了京津冀地区在两种 气候情景和 3 种发展情景下电力部门的能源 - 水耦 合关系, 分析能源结构调整和技术进步在缓解区域 水资源压力和促进可持续发展方面的潜力 [2]。

与上述模型相比, LEAP-WEAP 模型对于城市 尺度下的能水耦合分析具有一定的优势。LEAP 和 WEAP 模型基本的原理是质量平衡原理, 可以同时 从供给侧与需求侧出发, 考虑能源与水资源情况, 且具有情景分析工具。与系统动力学模型相比, 在 水资源供给模拟方面 WEAP 内置有强大的水文分 析工具, 可以做到对河流径流、取水点、输水距离 等细节的模拟。与可计算一般均衡模型相比, 其用 户体验友好, 操作较为简单。与改进的能源模型与 水资源模型相比, LEAP-WEAP 内置数据传输功能, 可以共享核心参数以及能水模拟结果, 为耦合分析 提供了便利。

LEAP 与 WEAP 结合模型的建立过程与上述模 型相比也存在一些难点, 首先在各自的部门设置方 面, 需要细致的部门活动水平、用水/用能强度、 发电机组容量、转换效率、水文径流量、下渗率等 数据。在各自能源与水资源的关联方面, LEAP 与 WEAP 结合的模型是通过数据传输来实现的, 两者 在运行的过程中并非相互影响, 而是两者分别计算 的结果再交换数据输入整体的模型中, 需要多次运 行才能得到最终结果。在情景设置方面, 相对可计
算一般均衡模型而言，考虑碳税、排污权交易等经 济节能 / 减排手段具有一定的难度。

在上述提及的利用 LEAP-WEAP 耦合模型的 论文中, 情景的设定通常基于各自的参考文献以及 作者本身的假设, 若将其情景设置的方向进行总结 可以得到以下几个方面: (1)经济发展情况: 设定不 同经济增速以及不同产业结构。(2)技术进步：主要 体现在强度的下降, 包括单独用水强度的下降、单 独的能源强度下降以及两者同时下降。(3)气候变 化模式: 包括 RCP4.5 与 RCP8.5 等, 通常是通过 对 WEAP 的供水情况产生影响进而影响整个系统。 (4)能源结构改变: 包括发展核能、生物质能源、 水电、天然气等措施。(5)供水优先度改变: 设定 优先使用本地水资源或者优先使用进口水资源, 优先使用地表水资源或者地下水资源等。北京城 乡的情况与文献研究的城市存在差异, 因此在参 考以上分析的同时, 地方规划与政府文件也具备 较高的参考价值。

\section{三、模型构建方法}

在对研究空间范围进行界定时, 假设北京市的 能源 (或水) 需求通过城市边界内和跨境资源供应 来满足。在本研究中只计算能源 (或水) 的直接消 耗, 不考虑远距离输电 (跨流域调水) 的用水 (用 能)。在能源系统中包括取水 (本地地下水与地表 水)、净化水、供水、污水处理的能源需求, 而水 系统包括用于火力发电、水力发电、风力发电、光 伏发电、生物质发电过程中的水耗, 但不包括外调 电力在生产地进行生产时的用水。

在研究年份上, 由于可获取的基础数据与发 电行业技术参数等在年份上需要统一, 因此选择 了 2015 年作为基准年份, 预测 2015-2050 年北 京市中长期能源与水资源利用以及耦合情况, 步 长为一年。

\section{（一）WEAP 与 LEAP 耦合模块}

WEAP 和 LEAP 作为协同工具, 共享许多相同 的设计特性和方法, 且由彼此密切协作的软件团队 创建。WEAP 和 LEAP 共享以下功能: 软件平台 (Delphi)、紧密协调的术语、基于 Windows 公共对 
象模型（COM）的紧密集成的应用程序编程接口 (API)、用于数据输入和输出的相似用户界面、用 于输入数据和创建模型的相似数据定义语言、用于 场景管理的相似方法等。

通过使用 LEAP 或者 WEAP 中的 Advanced: Link 功能, 在 WEAP 区域和 LEAP 区域之间建立 连接。将 WEAP 区域链接到 LEAP 区域后, 可以 使用表达式中的 LEAP Value 函数从 LEAP 读取数 据和结果。反之, 将 LEAP 区域及连接到 WEAP 区 域之后，可以使用表达式中的 WEAP Value 函数从 WEAP 中读取结果。

在本研究中, LEAP 与 WEAP 的部门设置概要 可以参考能水耦合模型分析框架。对于具体的模型 连接, 从 WEAP 到 LEAP, 水的取用、净化、供应、 污水处理情况是关键环节。在 WEAP 模型中预测了 供水总量, 依据供水总量估算水在泵取、输送、处 理过程中的能源消耗, 每一个环节都存在对应的能 耗强度可供参考 [18]。

从 LEAP 到 WEAP, 能源转换模块的用水量是 关联的重点。利用 LEAP 模型能源结构预测的结果, 可以计算出不同发电方式的发电需求。在关联模型 中, 将该需求量输入 WEAP 模型。在 WEAP 模型中, 可以建立不同一次能源转换的用水强度作为参数, 参数参考文献 [18] 的研究。通过这种方式, WEAP 和 LEAP 分别对水和能源的描述可以成功地联系起 来, 模拟能源 - 水资源系统的相互作用, 总结如 图 1 所示。

\section{（二）政策耦合模块}

本模型立足于北京城乡的实际情况, 试图建立 部门划分详细, 具有北京特色, 能切实反映北京市 城乡未来能水情况以及耦合关系的模型。一方面, 北京作为一个极度缺水, 且水资源供给依赖于他省 供给的大城市, 在远距离调水以及地下水取用过程 中的用能较大, 在本模型中将水的生产供应业详细 划分为取水、制水、污水处理、回收水处理四个部 分, 取水又细分为地表水取水、地下水取水、南水 北调水取水三个过程。此外, 作为常住人口超过 2000 万的大城市，居民生活过程中的能水耦合情况 同样值得重点关注, 本模型计算了居民生活过程中 洗浴、饮用水加热、洗衣过程中的用水量。政策数 据传输路径, 如图 2 所示。

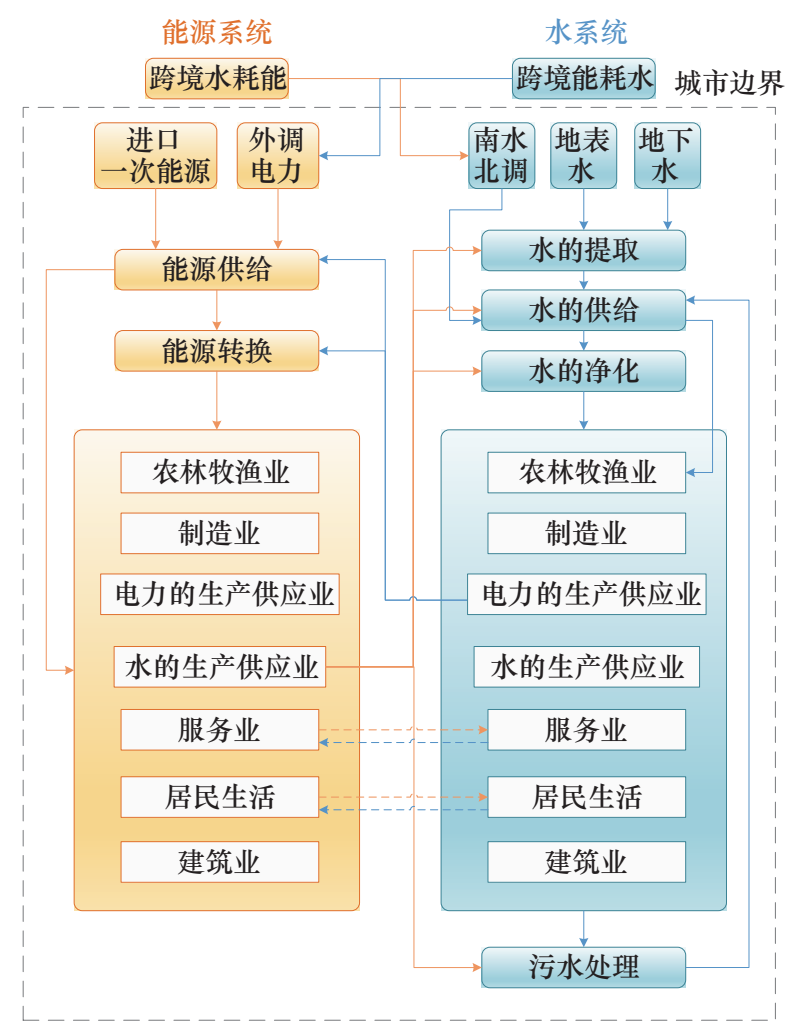

图 1 能水耦合模型分析框架

\section{（三）情景设置}

本研究情景设计的思路是先在 LEAP 与 WEAP 中分别设立基准情景（BAU）。设置的原则是按 照核心参数设定的活动水平以及目前的强度外推, 不加任何干预措施。在这一情景的基础上, 设置 23 个子情境, 分别探讨单个政策下的节能节水效 果，以及两者的协同效应。综合 6 个部门子情境分 别在 LEAP 与 WEAP 中建立参考情景 (REF), 试 图对最贴近实际的情况进行模拟; 另一方面, 立足 于北京的地下水过度开采的实际情况，设立了基于 参考情景下的限制地下水开采、再生水利用率提高 等两个水资源供给端的情景。目前，北京正在进行 大兴国际机场的建设、冬季奥林匹克运动会的筹备 等重大活动, 本模型将这一点考虑在内, 对新机场 建设、冬季奥林匹克运动会带来的冰雪产业发展情 景下的能水需求进行预测。

\section{四、研究结果}

\section{（一）部门能水耦合分析}

图 3 为各个部门用水需求与能源需求的散点图。 
从图 3（a）中分部门来看, 居民生活与服务业部门 既有较高的用水需求, 又有较高的能源需求。具体
来看, 居民生活部门能源需求在 $1 \times 10^{7} \sim 1.5 \times 10^{7}$ tce, 水需求量在 $8 \times 10^{8} \sim 1 \times 10^{9} \mathrm{~m}^{3}$, 用水需求与用能需
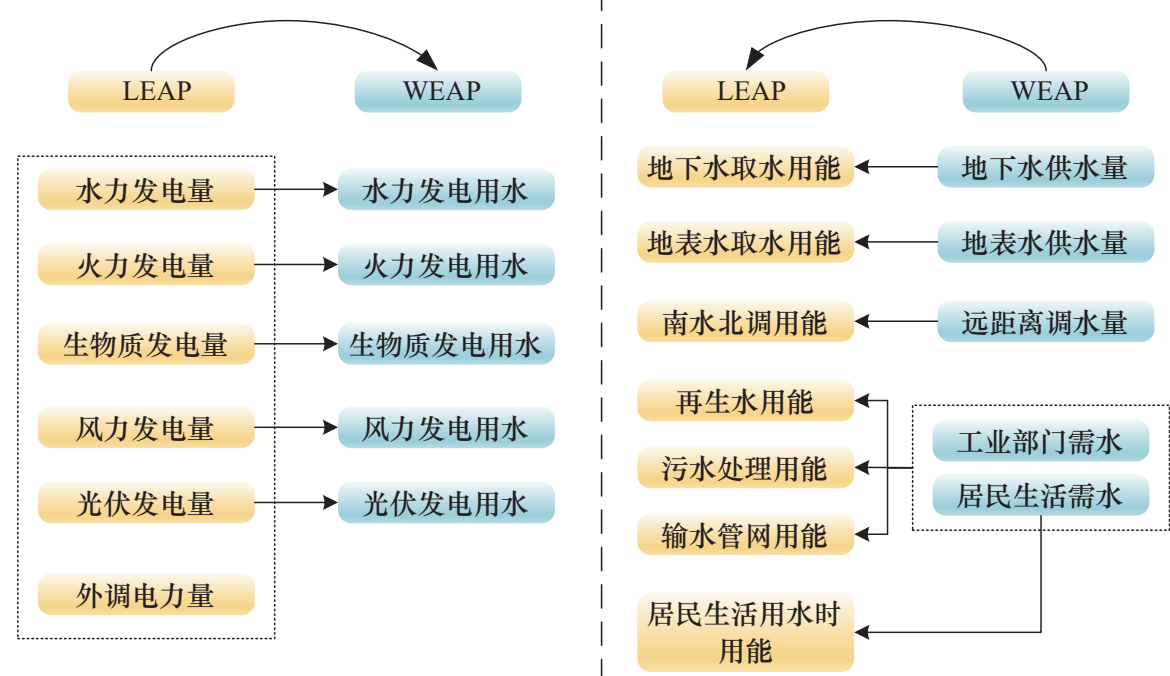

图 2 政策数据传输路径

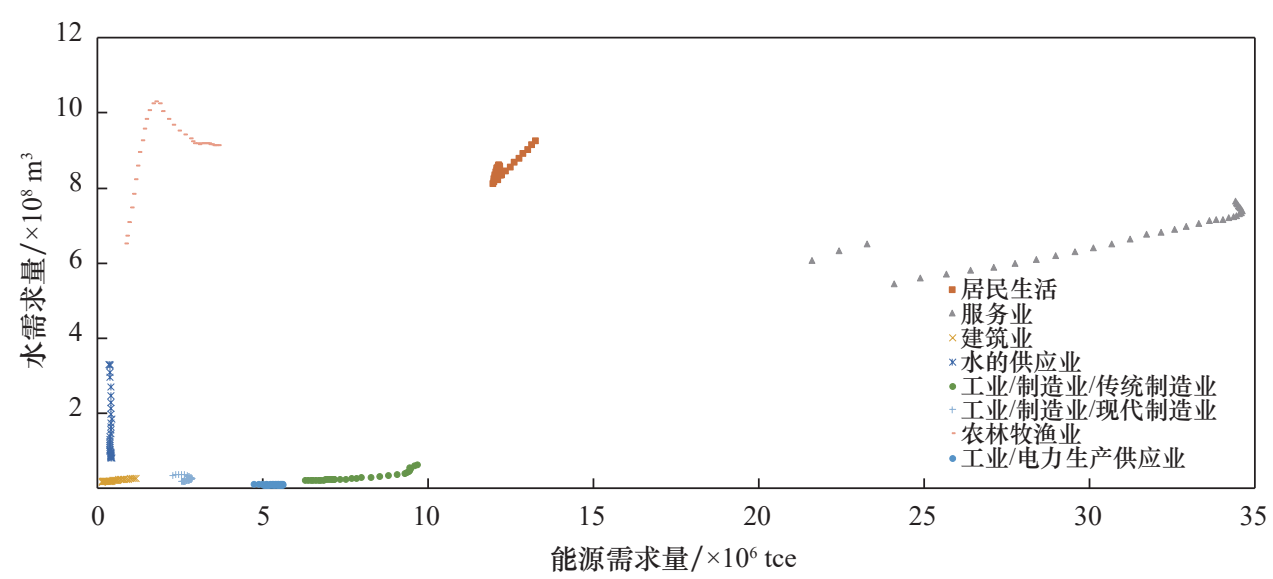

(a)

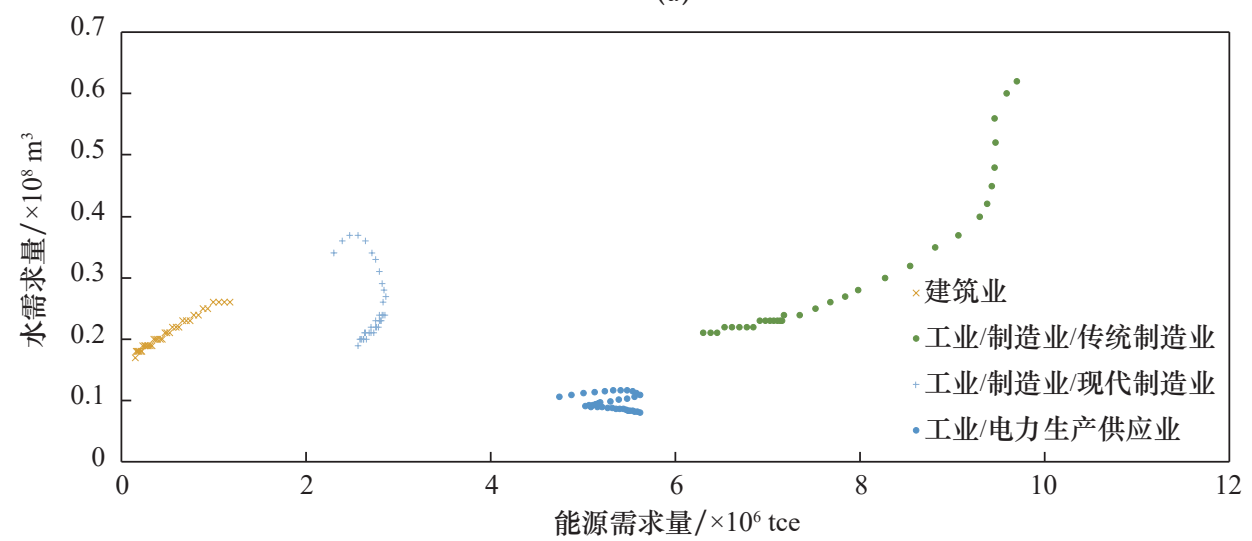

(b)

图 3 参考情景下预测周期内各部门能水需求量 注: 图中轨迹为北京城乡 2015-2050 年预测结果。 
求之间存在正相关的关系。服务业用水需求与用能 需求同样存在相关关系，若进行回归分析，其拟合 回归曲线斜率较居民生活部门低，居民生活与服务 业分别为 $0.693\left(R^{2}=0.8216\right)$ 与 $0.140\left(R^{2}=0.78\right)$, 即单位能源使用伴随着的用水量较小。农业部门用 水需求量较高, 其用能需求量与其他部门相比并不 高。水与能源使用量之间不存在明显的正相关关系。 当 2029 年能源需求量增长至 $1.668 \times 10^{6}$ tce 时, 水 的需求量达到最高, 为 $1.023 \times 10^{9} \mathrm{~m}^{3}$, 之后水的需 求量降低。水的供应业部门从图上来看即使水的需 求量增加, 能源需求量也未出现明显的变化。可 能是因为在这部分中南水北调的能源消耗未计入 该部门的能源需求中, 若计入, 两者或许有更明 显的相关性。

由图 3 (b) 可看到，建筑业、传统制造业、现 代制造业、电力生产供应业部门更详细的能水耦合 情况, 其中建筑业的能源与水利用呈正向的线性相 关关系 $\left(R^{2}=0.9801\right)$ 。传统制造业在能源增长的迁 移水需求也出现了增长, 在后期水需求增速缓慢甚 至在某些年份出现了下降。现代制造业部门水资源 需求量变化明显而能源需求量未出现明显的变化。 电力生产供应部门能水关系呈现了波动的状态, 即 一段时间内能源需求与水资源需求同时增加, 一段
时间内能源需求增加水资源需求下降，一段时间内 两者同时下降，这种关系的出现是因为外调电力的 影响, 在 WEAP 模型中电力生产与供应部门的用 水活动水平来自 LEAP 转换部分的电力生产值, 外 调电力的影响下电力的生产量下降而总的电力消 费量可能是上升的, 而 LEAP 中的电力生产与供 应部门是与电力总需求量相关的, 因此两者呈现 波动状态。

综上，居民生活、服务业、建筑业、传统制造 业在能源需求量与水需求量上具有较好的相关性, 用能与用水较为同步, 是重要的能水耦合部门。

\section{（二）节能目标情景下的节水效果}

在节能目标情景下（见图 4), 服务业终端技术 革新情景具有最好的节水效果，至 2050 年节水比 例达到 $6.85 \%$ 。外调绿电措施同样具备较好的节水 效果，在 2050 年节水比例为 $5.67 \%$ 。从节水效果 随时间的变化来看，外调绿电在 2015-2020 年节 水量迅速上升, 2020-2050 年下降的速率将减缓, 其在 2020 年出现拐点的原因是 2015-2020 年火力 发电的占比从 $30 \%$ 左右缩减至 $10 \%$, 此后逐年变 化 $0.3 \%$, 直至火力发电被完全取代。

此外, 电动汽车推广、建筑新能源使用、服务

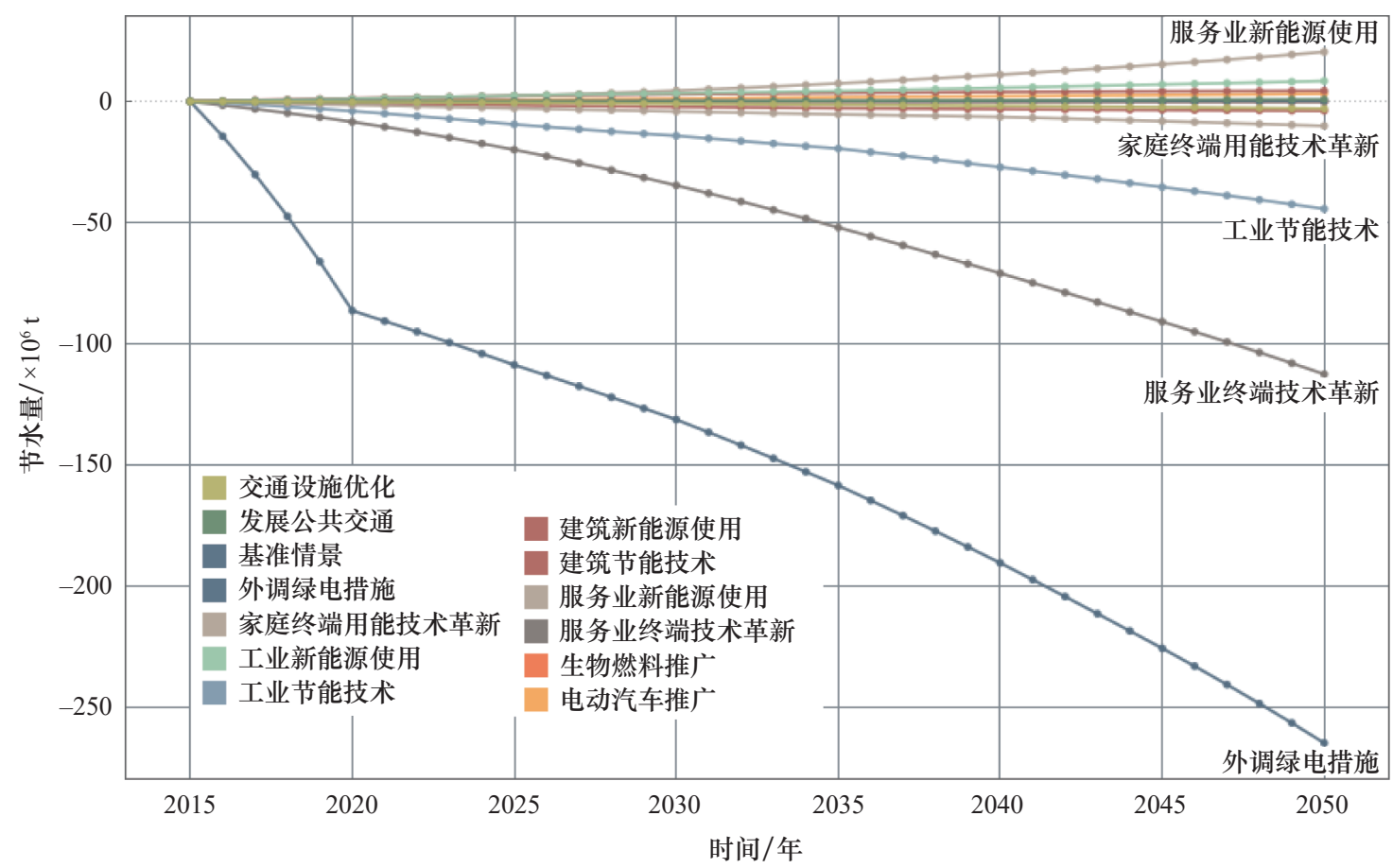

图 4 节能目标情景下的节能效果 
业新能源使用、工业新能源使用等措施较基准情景 而言带来了新的用水需求。其中服务业新能源使用 情景在 2050 年将带来 $2 \times 10^{7} \mathrm{~m}^{3}$ 的用水需求, 占总 用水需求的 $0.44 \%$ 。其次是工业新能源使用 $0.18 \%$, 建筑新能源 $0.10 \%$, 电动汽车推广 $0.07 \%$ 。电动汽 车推广一方面带来能源需求总量的下降, 另一方 面带来电力占比的上升, 两者中和后总的电力需 求量还是上升。发电量的增加, 进而带来发电用水 的需求。

\section{（三）节水目标情境下的节能效果}

在节水目标情景下 (见图 5), 总体能源需求节 约量最多仅占总能源需求量的 $0.66 \%$ 。不同的情景 下, 短中长期节能效果变化有所不同。从短期效果 来看, 至 2020 年工业节水措施具有最好的节能效 果, 接下来是种植结构优化、居民节水意识增强、 灌溉技术革新以及节水器具推广; 至 2025 年居民 节水意识增强的节能效果超过了种植结构优化, 节 水器具推广与灌溉技术革新达到了相同的节能效 果, 从 2025 年开始, 农业部门的两个节水政策的节 能量开始降低, 这一趋势持续至 2050 年。农业部 门出现拐点的原因是在 2025 年农业部门的结构优 化基本完成, 农业部门的用水量从 $6.89 \times 10^{8} \mathrm{~m}^{3}$ 减
少至 $4.05 \times 10^{8} \mathrm{~m}^{3}$, 地下水的取用量从 $1.7 \times 10^{9} \mathrm{~m}^{3}$ 减少到 $1.683 \times 10^{9} \mathrm{~m}^{3}$, 此时的节能量达到最大 值。而随着工业用水和服务业用水的继续增长, 地 下水的取用量重新上升, 至 2041 年上升稳定至 $1.7 \times 10^{9} \mathrm{~m}^{3}$, 因此节能量也趋于稳定。同理, 在基 准情景下供水量在 2040 年将不能满足所需水量, 而灌溉技术革新情景下至 2046 年才会出现供需的 缺口, 2040-2046 年由于供水量的上升, 能源的节 约量下降, 至 2046 年趋于平稳。

节水器具推广与居民节水意识增强情景在长 期展现出了较好的节能潜力, 至 2050 年其节能量 均超过 $1 \times 10^{6}$ tce。对于这两个政策而言, 能源的 节约主要来自于输水以及水处理过程中用能量的下 降, 其变化趋势与对应政策的节水量变化趋势一致。 工业节水措施的节能来源主要是工业再生水的处理 量下降, 因此带来的能耗下降, 与其节水曲线相比 节能曲线的下降趋势逐渐减缓, 2044 年后下降趋势 更明显, 出现拐点的原因是, 模型对取水量以及制 水量的估计是以水源的入流量作为活动水平进行估 计的, 而水处理量是以需求点的水需求作为活动水 平进行估计的。到 2044 年左右, 工业节水情景下 水资源的供需出现了缺口, 供水量不再发生变化, 此前在 2025-2044 年, 取水、制水节能量逐渐缩

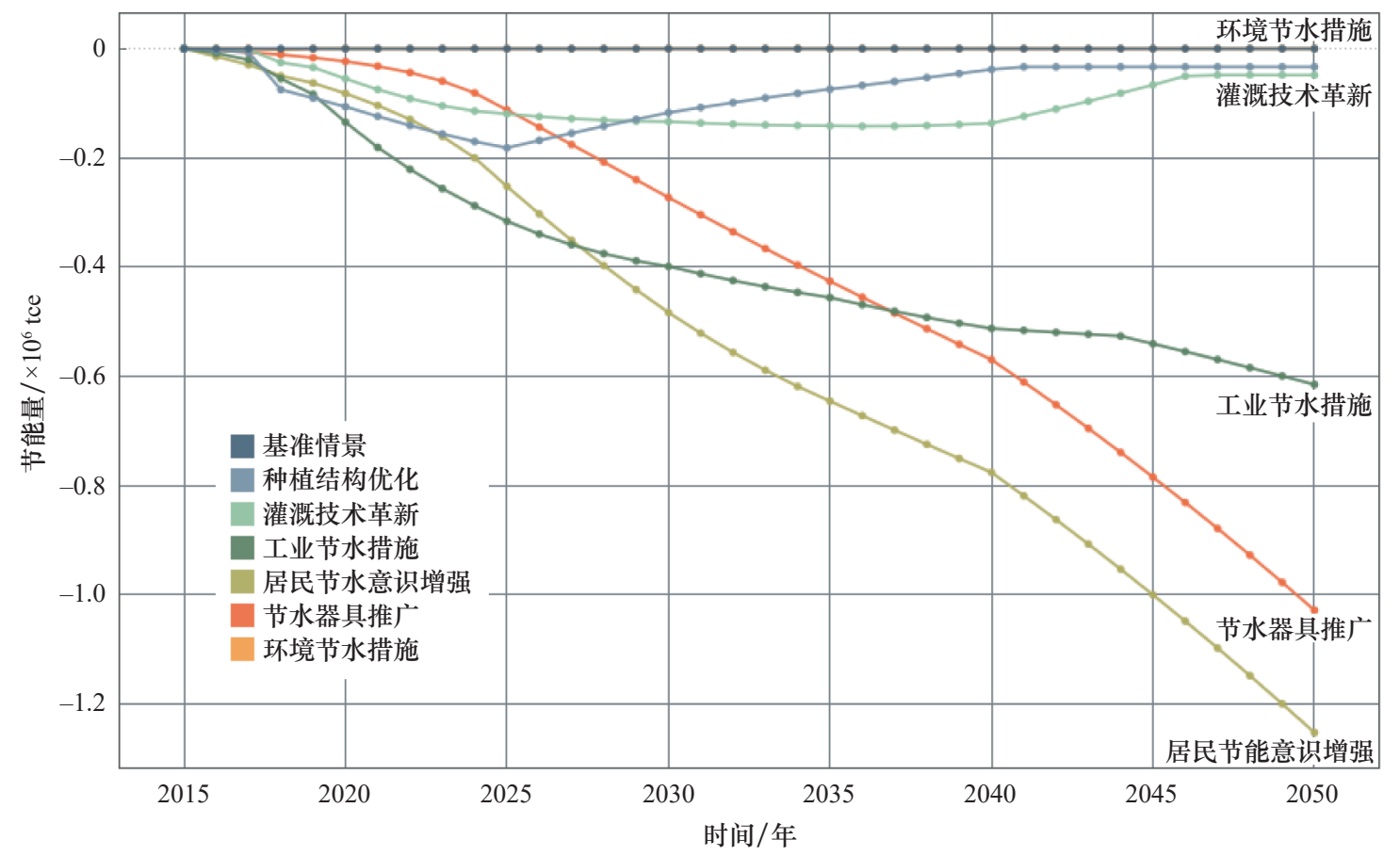

图 5 节水目标情境下的节能效果 
小, 使得总节能量呈缓慢下降趋势。2044 年后, 总 节能量的变化完全来自于污水排放处理以及再生 水处理等过程, 因此变化趋势更明显。由于在模 型的设置中, 环境用水不涉及取水、制水、输水、 污水处理以及居民终端用能耗水等环节, 所以不 具备节能效果。

综上, 农业部门的灌溉技术革新与种植结构优 化情景在短期内具有较好的节能效果, 然而随着用 水缺口的出现以及进一步扩大, 在中长期节能效果 不显著。工业部门节水措施短期也具有较显著的节 能效果，2018-2027 年在所有节水目标政策中，其 都具有最佳的节能效果, 从短期到中长期, 工业节 水措施的节能效果变化幅度较小。居民生活部门的 居民用水意识增强与节水器具推广措施在短期节能 效果均不显著, 自 2025 年后其节能量出现了明显 的增加, 分别在 2028 年与 2038 年超过工业节水措 施，从长期看具有较高的节能潜力。

\section{（四）不同政策情景下能水协同节约效果}

某些措施在制定时的目标虽然是节能或者节 水, 然而在政策实施的过程中可能会造成次生效应, 节能的政策可能减少了水的需求, 达到协同的效果, 也可能同时增加了水的需求。

总体而言，节能政策带来的节水比例大于节水 政策带来的节能比例，这是由用能过程中的水需求 比例本身高于用能过程中的水需求比例导致的。

对于部门政策而言，不同部门的节能/节水政 策协同效应不同，取决于该部门的用能与用水量。 对于服务业而言, 其耗能与耗水的比例均较高, 服 务业终端技术革新手段对节能与节水都具有较好的 效果 (分别为 $29.43 \%$ 与 $2.41 \%$ )。工业作为能源消 耗的主要部门之一，其节能政策对节水有较大的影 响, 工业技术革新情景下节能 $11.69 \%$, 节水 $0.95 \%$ 。 对于农业部门而言，单个部门的节能或者节水情景 协同效应均不明显。农业部门作为用水大户，节水 政策对能源节约没有太大的影响，一部分原因是工 业本身耗水耗能都较高, 而农业耗能较少; 另一部 分是因为能源在使用过程中的水占总用水的占比大 于用水过程中的能占总用能的占比。

即使是同一部门的政策，根据政策调控的变量 不同，其协同效果也有所不同。工业技术革新、服 务业终端用能技术革新、交通设施优化等调控用能
强度的情景展现出了一定的能水协同节约效应，而 能源结构优化（包括工业新能源使用、建筑业新能 源使用、服务业新能源使用）与产业结构优化政策 具有节能与减排效益，却增加了水的需求量。

对于同一个政策的不同档位而言，散点的分布 具有两种不同的方式，一种是单独的节能/节水效 果变化, 例如工业节水措施、灌溉技术革新等; 另 一种是具有能水协同效应的情景, 例如经济增速放 缓、工业技术革新、服务业终端技术革新等, 当节 能效果发生变化时, 节水效果也发生变化。

根据模型结果，“十三五” 期间北京市节能 政策的节水量达到 $2.76 \times 10^{8} \mathrm{~m}^{3}$ 。其中发展公共交 通, 新能源汽车推广, 工业、建筑业、服务业新能 源使用情景下水的需求增加量达到 $1 \times 10^{7} \mathrm{~m}^{3}$, 其 余政策的节水量达 $2.86 \times 10^{8} \mathrm{~m}^{3}$, 综合节水效果为 $2.76 \times 10^{8} \mathrm{~m}^{3}$, 约为北运河多年平均年径流量的一半, 相当于 140 个颐和园内昆明湖的蓄水量。节水政策 的节能量达到 $1.003 \times 10^{6}$ tce, 约等于 $8.165 \times 10^{9} \mathrm{~kW} \cdot \mathrm{h}$ 的电力, 为 2017 年北京全社会总用电量的 $7.65 \%$ 。

\section{（五）重大活动以及基础设施建设的节能节水效果}

北京新机场已于 2019 年投入运营, 同年也举 办了世界园艺博览会。2022 年北京一张家口联合 申报的冬季奥林匹克运动会也将如期进行, 未来重 大活动以及基础设施的建设将带来新的用能用水压 力。模型结果表明, 北京大兴国际机场、冬季奥林 匹克运动会、世界园艺博览会、环球影城等项目的 新建每年将增加 $5 \%$ \% $\%$ 的能源需求。在冰雪运动 发展的情景中, 冬季奥林匹克运动会带来的冰雪 产业发展将会带来不超过 $1 \%$ 的用水增长，年均约 $2.6 \times 10^{7} \mathrm{~m}^{3}$ 。应该在以上工程项目进行的过程中尽 可能提高能水利用效率。

\section{五、结论与建议}

本文基于 LEAP 和 WEAP 工具建立了具有北 京城乡特色的能水耦合模型, 并应用情景分析探讨 未来不同相关措施的节能 / 节水以及两者协同的效 果, 基于此模型可对城市能水耦合过程以及机制有 更清晰的了解。

在参考情景下中, 与用水有关的能源需求包 括水的取用、供给、输送以及居民生活用水过程中 
的能源需求, 合计为 $7.12 \times 10^{6}$ tce (2050 年数值), 预测期内（2015-2050 年）平均占总能源需求的 $7.74 \%$ 。其中居民用水过程中能耗平均占 $14.48 \%$, 取水平均占比 $45.48 \%$, 制水占 $4.15 \%$, 输水占 $12.43 \%$ ，污水排放处理占 $2.41 \%$, 污水再生利用占 $21.05 \%$ 。与用能源有关的水需求主要是发电过程中 的需水, 2050 年为 $6.8 \times 10^{7} \mathrm{~m}^{3}$, 预测期内平均占 总能源需求的 $2.45 \%$ 。其中火力发电平均占 $81.7 \%$, 水力发电占 $17.13 \%$, 其余发电方式占 $1.17 \%$ 。

从部门的能水耦合关系来看，居民生活、服务 业、建筑业、传统制造业在能源需求量与水需求量 具有较好的相关性, 用能与用水较为同步, 是重要 的能水耦合部门。

核心参数改变情景与节水目标情景在短中长期 呈现出不同的节能/节水效果, 以产业结构优化政 策为例, 短期其表现出了较好的节能潜力, 同时在 短时间内增加了用水的压力。中长期节能效果不明 显, 但仍伴随有用水量的增加, 因此想要通过产业 结构优化达到节约资源，应该合理调整产业结构调 整的方向。农业部门的灌溉技术革新与种植结构优 化情景短期具有较好的节能与节水效果，中长期节 水效果稳定, 然而随着总用水缺口的出现以及进一 步扩大，中长期节能效果不显著。进一步的敏感性 分析的结果表明, 经济增速放缓、产业结构优化、 发展公共交通、种植结构优化等情景调控的参数对 于最终的节能/节水量都具有较大的影响, 参数敏 感性较高。

对能水节约的协同效应，不同部门的节能/节 水政策协同效应不同，取决于该部门的用能与用水 量。对于服务业和工业部门而言, 其节能情景同样 具有节水效果。对于农业部门而言, 单个部门的节 能或者节水情景协同效应均不明显。即使是同一个 部门的政策，根据政策调控的变量不同，其协同效 果也有所不同。调控用能强度的情景展现出了一定 的能水协同节约效应，而能源结构优化（包括工业 新能源使用、建筑业新能源使用、服务业新能源使 用）与产业结构优化政策具有节能与减排效益, 却 增加了水的需求量。

若同时考虑政策的综合效果与实施难度，工业 部门的节能政策对综合评估而言有较大的贡献，然 而工业节水、节能政策具有一定的实施难度。相对 而言，发展公共交通政策在节能政策中具有最低的
实施难度，居民节水意识增强措施在节水政策中具 有最低的实施难度。在政策评估过程中, 外调电力 政策的表现较为突出，从综合效果评估与政策的实 施难度来考虑，都具备一定的优势。未来应在保障 供电安全与稳定性的前提下加大外调电力的比例。 此外, 在北京大兴国际机场、冬季奥林匹克运动 会等重大活动与基础设置建设过程中的能源与水 需求也应该关注。

\section{参考文献}

[1] 白鹏, 刘昌明. 北京市用水结构演变及归因分析 [J]. 南水北调 与水利科技, 2018, 16(4): 1-6.

Bai P, Liu C M. Evolution law and attribution analysis of water utilization structure in Beijing [J]. South-to-North Water Transfers and Water Science \& Technology, 2018, 16(4): 1-6.

[2] 潘柏林. 京津冀区域能源-水关系研究: 电力部门 [D]. 北京: 清 华大学(博士学位论文), 2017.

Pan B L. Study on energy-water relationship in Beijing-Tianjin-Hebei region: Power sector [D]. Beijing: Tsinghua University (Doctoral dissertation), 2017.

[3] 顾阿伦, 滕飞. “十一五”期间中国主要工业部门节能的节水效 果分析 [J]. 资源科学, 2014, 36(9): 1773-1779.

$\mathrm{Gu}$ A L, Teng F. Effects of pollution control measures on carbon emission reduction in China: Evidence from the "11th Five-Year Plans" [J]. Resources Science, 2014, 36(9): 1773-1779.

[4] 梁赛, 王灿. 北京市节水技术的节能效应分析 [J]. 节水灌溉, 2007 (4): 39-40.

Liang S, Wang C. Analysis of energy-saving effect of water-saving technology in Beijing [J]. Water Saving Irrigation, 2007 (4): $39-40$.

[5] Qin Y, Curmi E, Kopec G M, et al. China's energy-water nexusAssessment of the energy sector's compliance with the "3 Red Lines" industrial water policy [J]. Energy Policy, 2015, 82: 131143.

[6] 赵志刚. 基于法规约束的北京节水成效及政策建议 [J]. 中国水 利, 2019 (3): 13-15.

Zhao Z G. Water saving effect and policy suggestion based on regulation [J]. China Water Resources, 2019 (3): 13-15.

[7] 丁志宏, 唐肖岗, 杨婷. 南水北调通水后的海河流域水资源配置 与调度管理研究工作若干思考 [J]. 海河水利, 2017 (3): 1-7.

Ding Z H, Tang X G, Yang T. Some thoughts on water resources allocation and dispatching management in Haihe river basin after the diversion of water from south to north [J]. Haihe Water Resources, 2017 (3): 1-7.

[8] Hussey K, Pittock J. The energy-water nexus: Managing the links between energy and water for a sustainable future [J]. Ecology and Society, 2012, 17(1): 293-303.

[9] Zhou Y, Zhang B, Wang H, et al. Drops of energy: Conserving urban water to reduce greenhouse gas emissions [J]. Environmental Science and Technology, 2013, 47(19): 10753-10761.

[10] Fan J, Kong L, Zhang X. Synergetic effects of water and climate policy on energy-water nexus in China: A computable general 
equilibrium analysis [J]. Energy Policy, 2018, 123: 308-317.

[11] Zhou Y, Li H, Wang K, et al. China's energy-water nexus: Spillover effects of energy and water policy [J]. Global Environmental Change, 2016, 40: 92-100.

[12] Khan Z, Linares P, García-González J. Integrating water and energy models for policy driven applications: A review of contemporary work and recommendations for future developments [J]. Renewable \& Sustainable Energy Reviews, 2017, 67: 1123-1138.

[13] Suárez F, Muñoz J F, Fernández B, et al. Integrated water resource management and energy requirements for water supply in the Copiapó river basin, Chile [J]. Water, 2014, 6(9): 2590-2613.

[14] Mehta V, Yates D. Integrated water-energy-emissions analysis: Applying LEAP and WEAP together in California [R]. California: Water-Energy-Food Nexus, 2012.
[15] Agrawal N, Ahiduzzaman M, Kumar A. The development of an integrated model for the assessment of water and GHG footprints for the power generation sector [J]. Applied Energy, 2018, 216: $558-575$.

[16] Lin J, Kang J, Bai X, et al. Modeling the urban water-energy nexus: A case study of Xiamen, China [J]. Journal of Cleaner Production, 2019, 215: 680-688.

[17] Li X Y. Understanding the water-energy nexus: A case study of Ningxia [D]. Uppsala University (Doctoral dissertation), 2014.

[18] 姜珊. 水-能源纽带关系解析与耦合模拟 [D]. 北京: 中国水利水 电科学研究院(博士学位论文), 2017.

Jiang S. Scientific concept of water-energy nexus and coupling simulation [D]. Beijing: China Institute of Water Resources \& Hydropower Research (Doctoral dissertation), 2017. 